\title{
Otredad, diversidad religiosa y prejuicios en las interacciones cotidianas de evangélicos/as de Córdoba, Argentina
}

\author{
Hugo H. Rabbia*
}

\section{Resumen}

El trabajo explora cómo personas evangélicas de Córdoba, Argentina, perciben su posición social, interacciones de contacto intergrupal, y los modos en que buscan gestionar la otredad, en un contexto de creciente visibilidad de la diversidad religiosa y no religiosa. A partir de narrativas autobiográficas de 23 entrevistados se describen diversas interacciones sociales con "otros" religiosos y no religiosos en espacios laborales, de militancia, educativos, y sociales. Resulta extendida la percepción de estereotipos negativos hacia evangélicos/as, a la vez que emergen diversas narrativas personales de prejuicios (aislamiento, hostigamiento o animosidad) de la que han sido objetos. Las estrategias para gestionar esas interacciones dependen de cada espacio social y cada persona, y pueden implicar la compartimentalización, la participación resignificada, o incluso la evitación de la diversidad religiosa, entre otras.

Palabras clave: prejuicios religiosos, otredad, evangélicos, diversidad religiosa, estereotipos.

\footnotetext{
*Universidad Nacional de Córdoba y Universidad Católica de Córdoba, Córdoba, Argentina.
} 


\section{Otherness, religious diversity and prejudices in daily interactions of evangelicals in Córdoba, Argentina}

\section{Abstract}

The paper explores how evangelicals from Córdoba, Argentina, perceive their social position, intergroup contact interactions, and the ways they seek to manage otherness, in a context of increasing visibility of religious and non-religious diversity. Based on autobiographical narratives by 23 respondents, we describe different social interactions with religious and non-religious "others" in work, militancy, educational, and social contexts. The perception of negative stereotypes towards evangelicals is extended, as several personal narratives of prejudices (isolation, harassment or animosity) toward them emerged. The strategies to manage these interactions depend on each social context and each person, and may involve compartmentalization, re-signified participation, or even the avoidance of religious diversity, among others.

Keywords: religious prejudice, otherness, evangelicals, religious diversity, stereotypes.

\section{Introducción}

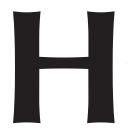

ace ya tres décadas, un nutrido conjunto de trabajos afirmó la tendencia a un "giro protestante" en América Latina, una región que había sido concebida y analizada desde la predominancia histórica y social de la Iglesia Católica (Martin, 1990; Stoll, 1990). Desde entonces, diversos estudios han sumado evidencias respecto a que la región, con particularidades en cada contexto, tiende a una mayor pluralidad religiosa, donde las y los evangélicos representan un incremento significativo (De la Torre; Gutierrez-Zuñiga, 2008; Levine, 2005; Parker-Gumucio, 2005; Pew Research Center, 2014; Romero, 2016; Somma; Bargsted; Valenzuela, 2017; Suárez, 2015).

La reciente difusión de resultados preliminares de la Segunda Encuesta Nacional de Creencias y Actitudes Religiosas ha permitido cuantificar algunas 
de estas transformaciones para la sociedad argentina (Mallimaci et al., 2019). Los datos señalan una diversificación de las adscripciones religiosas, a partir de un descenso de católicos/as (pasa de 76,5\% en 2008 a 62,9\% en 2019), y un aumento entre quienes se identifican como evangélicos/ as (de $9 \%$ a $15,3 \%$ ) y entre quienes no se identifican con una religión de pertenencia (los "sin religión" eran 11,3\% en 2008 y 18,9\% en la segunda ola). También ha descendido la creencia en Jesucristo y en Dios, aunque aún representa a ocho de cada diez personas encuestadas, mientras que continúa siendo mayoritaria la idea de que la relación privilegiada con Dios se da "por cuenta propia" (Mallimaci et al., 2019). Las creencias y prácticas de las personas parecen a su vez disputar los mandatos de instituciones y líderes religiosos convencionales, puesto que se combinan elementos de diversas tradiciones en sus creencias, prácticas y actitudes. Dos de cada diez evangélicos, por ejemplo, creen en la Virgen María, y algo más de la mitad en las energías y, si bien la asistencia al templo es mucho más frecuente que entre católicos, algo más de un $17 \%$ señala que nunca concurre (Mallimaci et al. 2019). La información provista por este estudio permite visualizar en términos poblacionales y de dinámicas que la diversidad religiosa es una realidad para la sociedad argentina, y que se da tanto en el plano de la pluralidad de identificaciones religiosas y no religiosas, como en las prácticas, creencias y actitudes sociales de su población, incluso entre personas que se identifican como evangélicas.

Como fenómeno social, la diversidad religiosa argentina comienza a ser problematizada a partir de las décadas de 1980 y 1990, en especial desde los abordajes de los movimientos socio-religiosos y estudios desde las religiosidades populares. Así, el panorama del supuesto monopolio católico comienza a verse resquebrajado por la emergente visibilidad de los movimientos evangélicos, en especial, pentecostales, los movimientos de renovación carismática, las religiosidades afro-umbandistas, los circuitos de las nuevas espiritualidades (Carozzi, 2000; Frigerio, 1993; Forni, 1992; Marostica, 1994; Roldán, 1999) y los entramados de creencias y prácticas que coexisten en las vivencias cotidianas de las personas (Ameigeiras, 2008; Semán, 2018; Suárez, 2015).

La diversidad religiosa parece haber sido de largo aliento, aunque no haya sido visualizada. A su vez, como advierten Frigerio y Wynarczyk 
(2008), no debe ser confundida con el pluralismo religioso, que supondría también una valoración positiva de esa diversidad y una desregulación del mercado religioso. En Argentina, la Iglesia Católica goza históricamente de una posición privilegiada en términos jurídicos, pero también, aunque cada vez más contestada, en su valoración social. Por ello, resulta destacable que la creciente visibilidad de religiosidades no católicas, evangélicas y afro-umbandistas en particular, emerja en el marco del "problema de las sectas" y las consecuentes demandas por una mayor regulación estatal (Frigerio; Wynarczyk, 2008). Así, como advierten los autores, las primeras reacciones frente al crecimiento del número de personas evangélicas las situaron en una posición de un "otro" cuestionado por su presunta peligrosidad (Frigerio; Wynarczyk, 2008).

Las y los evangélicos cuentan con una historia de, al menos, doscientos años en la sociedad argentina. Como algunos trabajos han documentado, la inserción de iglesias evangélicas ha respondido a diversas "vertientes" y "momentos", con una expansión prolongada, aunque casi imperceptible, y un momento de mayor visibilidad a partir del retorno de la democracia en los años ochenta (Deiros, 2013; Wynarczyk; Semán, 2018; Míguez, 2018). La noción de "evangélicos" constituye un "rótulo genérico" que, como señala Semán (2019), se ha ido imponiendo para dar cuenta de las diversas corrientes y grupos religiosos que se consideran herederos del cisma protestante del siglo XVI. Si bien con una gran heterogeneidad, estas iglesias se diferencian del catolicismo por rechazar la autoridad papal y basar la autoridad religiosa de forma exclusiva en la Biblia, como palabra de origen divino. En la región, se han evidenciado al menos tres grandes momentos o vertientes: los denominados protestantismos históricos que arriban durante el siglo XIX, las tendencias evangelicales, misioneras y con fuerte literalismo bíblico, que aparecen a inicios del siglo XX, y los pentecostalismos que, aún con antecedentes previos, adquieren mayor relevancia a partir de mitad del mismo siglo y que han basado su expansión como movimiento religioso, sobre todo entre los sectores populares, en sus recursos litúrgicos y en una doctrina que prioriza los liderazgos carismáticos (Míguez, 2018; Wynarczyk; Semán, 2018).

A lo largo de los últimos treinta años, el evangelismo en Argentina ha tendido a una mayor "pentecostalización", debido a la incidencia numérica 
y las estrategias de reclutamiento de los pentecostales (Wynarczyk; Semán, 2018). También las muy diversas iglesias evangélicas han comenzado a tejer una red de presencias públicas, desde actos de oración masivos, mayor incidencia en agencias de regulación estatal, como las secretarías de culto, la promoción - infructuosa - de diversos proyectos de ley de libertad religiosa, y las amplias movilizaciones sociales contra iniciativas legislativas o políticas de derechos sexuales (como las que promovieron el matrimonio igualitario, la legalización del aborto, o la modificación del Programa Nacional de Educación Sexual Integral) (Carbonelli, 2016; Jones; Carbonelli, 2015; García-Bossio, 2016; Wynarczyk, 2009). En los últimos años, se ha advertido en diversos discursos públicos el reforzamiento de imágenes que asocian a los evangélicos con el fundamentalismo conservador y la derecha ideológica (Flores, 2019; De la Calle, 2018).

En este sentido, los evangélicos se constituyen como un "otro" religioso significativo en los debates sobre diversidad religiosa en Argentina. A diferencia de lo que acontece, por ejemplo, en Europa Occidental, donde el "otro" (árabe o norafricano) se configura desde una otredad también "étnica" o "racial", en nuestro contexto el "otro" aparece como alguien relativamente parecido a cada uno de nosotros (Morello; Rabbia, 2019), lo cual permite pensar que los procesos de diferenciación se basan mayormente en estereotipos y prejuicios de carácter religioso.

La identificación de un "otro" frente a un "nosotros" constituye un proceso típico de diferenciación intergrupal y de conformación de identidades sociales. Se presenta tanto en los procesos de categorización social, comparación social y la búsqueda de distintividad psicológica (Tajfel, 1984), como en dinámicas sociales de mayor alcance, donde ciertos grupos con posición dominante se embarcan en procesos de diferenciación y demarcación entre un "nosotros" y un "ellos" (subalterno) donde las distancias sociales son demarcadas y sostenidas (Lister, 2004). Desde la etnolingüística se ha cuestionado a las teorías de la identidad social basadas mayormente en procesos psicológicos para enfatizar también cómo, a partir de diversos procesos discursivos, los grupos poderosos de una sociedad configuran un "otro" (othering), usualmente étnico y/o religioso (Jensen, 2011). La otredad refleja las experiencias y sentimientos compartidos de los grupos subalternos que, en parte, configuran su identidad a partir de y en 
relación con los marcos representacionales estereotipados y generalizantes que se imponen en un contexto dado. No obstante, como señala McNamara (1997), la perspectiva de la identidad social formulada por Tajel (1984) no implica desconocer el rol del contexto social en la conformación de procesos de diferenciación social, ya que las experiencias persistentes de actitudes negativas, de discriminación o la omnipresencia de símbolos y discursos de un grupo con status privilegiado son un recordatorio constante de la "otredad" de otros grupos.

El Mapa Nacional de Discriminación del Instituto Nacional Contra la Discriminación, el Racismo y la Xenofobia (INADI) señala que la discriminación religiosa constituye una problemática extendida en el país, aunque presenta mayor prevalencia hacia personas musulmanas (un 90\%) y judías (57\%). El 11\% de "evangelistas" (sic) reportaron haber sufrido y/o presenciado situaciones de discriminación por motivo de sus creencias (INADI, 2014). En 2017, el informe sobre denuncias de discriminación del Observatorio de Internet del INADI ubicó a las cuestiones religiosas como la principal causa de discriminación reportada en redes sociales digitales (En el Inadi..., 2017). A su vez, desde diversas religiones, se han cuestionado legislaciones y prácticas estatales que (re)producen una discriminación institucionalizada hacia minorías religiosas (Maioli, 2011).

Religión y prejuicios guardan una relación compleja. Por un lado, los estudios clásicos del prejuicio intergrupal, que reposan en los postulados de la personalidad autoritaria de Allport, parten de un prejuicio de índole religiosa: el prejuicio hacia judíos. El mismo autor advirtió lo que se conoce como las "paradojas de la religión" (Allport, 1966), el postulado de que no sólo la religión es objeto de estudio (el prejuicio religioso) sino también difusor de prejuicios, puesto que, aunque promueva el amor al prójimo y la tolerancia, al mismo tiempo (re)produce prejuicios hacia otros grupos raciales, étnicos, o sexuales. Si bien el estudio del prejuicio se ha complejizado a partir de la incorporación de diversas orientaciones religiosas (intrínseca, extrínseca y la dimensión quest) (Batson; Schoenrade, 1991), en los abordajes psicosociales las variables de religiosidad personal tienden a ser predictores habituales de diversos tipos de prejuicios, en especial, los prejuicios hacia personas gays, lesbianas o trans, y el sexismo (Etchezahar; Ungaretti; Rabbia, 2018; Páez et al., 2018). Por ejemplo, la Segunda Encuesta Nacional de Creencias y 
Actitudes Religiosas reportó que las personas evangélicas manifiestan casi el doble de proporción de acuerdo que la media de la muestra nacional con las ideas de que el único matrimonio válido es el de varón y mujer o que la mujer debe permanecer en su hogar para el cuidado de sus hijos (Mallimaci et al., 2019).

Probablemente debido al énfasis que ha adquirido una aproximación psicosocial, los prejuicios y la discriminación religiosa han sido escasamente abordados, con excepción quizás del antisemitismo. En Estados Unidos, estudios sobre prejuicios religiosos advierten que la población más degradada es la de ateos (Gervais; Shariff; Norenzayan, 2011; Cook; Cottrell; Webster, 2015), aunque también se han identificado prejuicios hacia grupos cristianos conservadores por parte de sectores progresistas, incluso cristianos (Yancey, 2010). En Nueva Zelanda, en cambio, son las personas evangélicas las que despiertan menor confianza relativa en el entorno social (Chapple; Prickett, 2019). En Europa occidental los trabajos se han focalizado mayormente en los prejuicios y la discriminación hacia musulmanes (Núñez-Alarcón; MoralToranzo; Moreno-Jiménez, 2010; Strabac; Listhaug, 2008). Griera i Llonch e Iglesias i Sala (2004) advirtieron, para el caso de Barcelona, que el prejuicio religioso no está homogéneamente distribuido: mientras algunas expresiones religiosas públicas son sancionadas - musulmanes - otras suelen despertar valoraciones positivas - budistas. Asimismo, las instituciones educativas suelen ser un terreno de prevalencia de prejuicios religiosos. Por ejemplo, en un estudio realizado en Inglaterra con adolescentes de confesiones anglicanas, bautistas y católicas, Moulin (2016) advirtió diversas expresiones de prejuicio anticristiano, algunas orientadas por sesgos institucionales de las propias instituciones educativas, los cuales afectaban la jerarquía en el grupo de pares de los adolescentes.

Como puede advertirse, los prejuicios religiosos difieren según contextos específicos, societales y de espacios de interacción. Es posible afirmar que cada sociedad (re)produce sus propios prejuicios a través de procesos históricos de configuración estereotípica de un "otro", que puede ser un "otro" religioso (Jensen, 2011; Hall, 1998/ 2010).

La discriminación es la expresión de prejuicios gestada en estas relaciones intergrupales contextualmente situadas. Discursos públicos (mediáticos, políticos, académicos) contribuirían a reforzar procesos de 
estereotipia, donde los "otros" se caracterizan a partir de generalizaciones excesivas, características negativas y degradantes. La hipótesis del contacto positivo entre grupos postula que las interacciones sociales pueden contribuir a reducir los prejuicios negativos y a resignificar los estereotipos hacia el exogrupo, aunque las condiciones requeridas no siempre son factibles de lograr a gran escala (Pettigrew, 1998; Etchezahar et al., 2018). A su vez, la percepción de una mayor diversidad religiosa no implica per se un mayor contacto significativo, ni mucho menos la eliminación de los prejuicios por el contrario, puede conducir a su exacerbación. En algunos casos, la percepción del "otro" como amenaza constituye un factor que reforzaría esos prejuicios (Cook et al., 2015).

En este artículo, nos proponemos explorar cómo las personas evangélicas perciben su posición social en un contexto de creciente visibilidad de la diversidad religiosa y no religiosa, a la par que indagar cómo y en qué espacios se dan situaciones de contacto intergrupal en las interacciones cotidianas de habitantes de la ciudad de Córdoba, Argentina. ¿Son estas interacciones positivas o, por el contrario, adoptan características de un prejuicio religioso? ¿Cómo se gestionan dichas interacciones? ¿Difieren según los espacios sociales de interacción: trabajo, institución educativa, amigos, comunidad religiosa etc.?

\section{Metodología}

El trabajo adoptó un diseño exploratorio transversal a partir de metodologías cualitativas. Los datos fueron recuperados de un estudio más amplio denominado Transformations of lived religion in urban Latin America ${ }^{1}$, donde Córdoba constituyó uno de los puntos de generación de evidencias, junto con Montevideo y Lima, y posteriormente Bilbao y Roma. Dicho estudio adoptó un enfoque narrativo desde la religión vivida, similar al desarrollado por Nancy T. Ammerman (2014) en su estudio en Boston y Atlanta, Estados Unidos. Las personas que participaron del estudio fueron seleccionadas por un muestreo teórico, vía bola de nieve, que contempló como criterios de segmentación la autoidentificación religiosa (evangélicas, católicas, sin religión y otras) y el nivel socioeconómico (bajo y medio/alto).

\footnotetext{
${ }^{1}$ La investigación fue financiada por The John Templeton Foundation grant $n^{\circ} .58079$.
} 
En este caso, se seleccionaron específicamente a las personas que se identificaron como evangélicas o cristianas evangélicas en el cuestionario filtro, o bien que indicaron que habían sido criadas en familias evangélicas $(\mathrm{N}=23)^{2}$. Estas últimas son dos mujeres que, si bien al momento de las entrevistas no recurrieron a la autoidentificación religiosa como "evangélicas", han atravesado experiencias de socialización y participación en iglesias evangélicas que se consideraron pertinentes recuperar para el análisis. Del total de casos considerados, 12 fueron varones y 11 mujeres. Las edades oscilan entre 19 y 70 años. Diez pertenecen a niveles socioeconómicos medios y altos, y 13, a bajos. En el Apéndice 1 se recoge información sobre las personas participantes del presente estudio, siendo que sus nombres responden al seudónimo escogido durante el proceso de consentimiento informado.

Cada participante fue entrevistado al menos en dos instancias: una primera entrevista que se propuso reconstruir desde narrativas autobiográficas la historia de vida de cada persona, con sus marcaciones, actores y puntos de inflexión; y una segunda entrevista donde se profundizó en otras narrativas espirituales, a partir de utilizar una técnica de elicitación de objetos.

En el presente estudio nos hemos focalizado mayormente en las narrativas de interacción social con personas de otras creencias, algunas de las cuales se configuran como narrativas personales de prejuicios (Hall, 1998/2010). Las mismas dan cuenta de los modos en que las propias personas identifican y dan sentido a diversas situaciones que atraviesan, las

\footnotetext{
${ }^{2} \mathrm{Al}$ inicio del proyecto, se categorizó a esta cuota del muestreo como "protestantes", dado que constituye una referencia más genérica e inclusiva, como hemos evidenciado. No obstante, salvo por un caso que congregó durante un tiempo en la Iglesia Metodista, no hemos entrevistado a personas que se identifiquen con tradiciones de los protestantismos históricos, las cuales tienen una presencia minoritaria en Córdoba. La noción de "evangélicos" permite incluir a personas que participan o participaron de iglesias de la segunda vertiente (las tradiciones evangelicales, como es el caso de Hermanos Libres), así como de la tercera vertiente, la de los pentecostalismos, que reflejan las identificaciones de la mayoría de nuestros entrevistados. A su vez, "evangélico" o "cristiano evangélico" fueron los rótulos preferidos por nuestros entrevistados al momento de autoidentificarse. Cabe destacar que un par de entrevistados se identificaron como "cristianos", pero esta etiqueta no es excluyente de los grupos que aquí identificamos como "evangélicos", puesto que algunas personas católicas de la muestra también la utilizaron para identificarse como una manera de remitir a una tradición religiosa que consideran más amplia y más relacionada con el mensaje originario de Cristo.
} 
cuales incluyen estereotipos, la configuración de otro desde la identificación de los propios sentimientos de otredad, así como situaciones manifiestas o sutiles de discriminación o animosidad. Las narrativas personales de prejuicios no fueron indagadas de forma guiada, sino que emergieron en diversos momentos en el marco de las narrativas autobiográficas. También consideramos algunos aspectos referidos a las prácticas religiosas en la vida cotidiana y a sus propias actitudes hacia "otros" (exogrupos) con el objeto de poder comprender las particularidades que puedan adoptar las situaciones de interacción social y las consecuencias que la misma depara en cada caso. Estos aspectos sí fueron orientados por las preguntas de la entrevista, como por ejemplo: ¿Cómo alguien puede darse cuenta de que sos cristiano/evangélico? o ¿Qué implica para vos ser no creyente/católico/ de otra religión?, entre otras. Estas situaciones se profundizaron en torno a diversos ejes espaciales: espacio laboral, espacio educativo, espacio de ocio (amistades), y espacio de militancia. Como podrá advertirse en la siguiente sección, durante los análisis emergió como espacio social significativo el tamaño y la ubicación de la localidad. No se reportan en este trabajo situaciones de interacción social interreligiosa o entre creyentes y no creyentes al interior de las familias. Se trata de una cuestión que ya hemos reportado en otros trabajos, aunque desde la perspectiva de las narrativas de personas católicas (Rabbia; Gatica, 2017).

\section{Resultados}

\section{"Era el único chico evangélico de mi edad"}

Lucas tiene 30 años al momento de las entrevistas, soltero y sin hijos. Estudió Comunicación Social y Letras Modernas y trabaja como corrector literario, a la par que ha publicado algunos libros de poesías y es músico. Es hijo de pastores evangélicos, y nació en un pequeño pueblo de la provincia de Santa Fe. "Se podría decir que de toda la vida estuve, estoy, atravesado por la fe cristiana y siempre como un hecho muy fuerte de identidad personal, familiar y comunitaria", afirma.

Cuando tenía seis años, su familia se mudó a un pequeño pueblo de la provincia de Córdoba. Los años que pasó en ese pueblo se vieron 
atravesados por el hostigamiento sufrido, y aún los recuerda con mucha angustia:

En este pueblito yo sufrí mucho, no por parte de maltrato familiar, sino fuera de mi casa. En esa época no se usaba la palabra bullying pero básicamente sería eso. Y ese bullying, que fue muy sostenido durante cinco años, fue sistemático y fue bastante violento durante toda la [escuela] primaria, y en buena parte estaba conectado con el hecho de que mis papás eran evangélicos y pastores de la única iglesia evangélica del pueblo (Lucas).

Allí, "en un pueblito profundamente católico, muy cerrado, muy sojero, muy campesino", como lo describe, evidenció por primera vez ser "otro", y se sintió hostigado y discriminado. "Yo era el hijo mayor, era el único chico evangélico [de] mi edad (...). Entonces eso hizo complicado, realmente complicado mi experiencia espiritual". Como se sentía muy solo, Lucas se preparó para poder adelantar un año del colegio, lo cual contribuyó a un mayor distanciamiento con sus pares. También pasaba mucho tiempo leyendo, mirando televisión o escuchando música de vinilos que heredó de sus padres. En la comunidad religiosa de ese entonces, tampoco encontró un espacio de acogida emocional:

Pasaba mucho tiempo en mi casa escuchando discos de los Bee Gees, The Beatles, Pink Floyd...y la gente de la iglesia, los feligreses, me la hacían pasar muy mal porque yo no podía hacer esas cosas, porque era el hijo de pastor. Entonces era otro motivo por el cual no los aguantaba y no aguantaba nada que tuviera que ver con esa instancia eclesiástica (Lucas).

La comunidad religiosa, a su vez, le parecía cargada de "inconsistencias con la forma en que vivían los cristianos", lo cual llevaba a acrecentar su ostracismo, y los sentimientos de marginación y exclusión.

En su relato, la evidencia de la propia alteridad en relación con el exogrupo (los compañeros de la escuela), pero también con el endogrupo (la comunidad religiosa), conllevó un proceso de poner en jaque sus experiencias de fe: "[h]asta los doce años yo no quise saber absolutamente nada con Dios".

Todo cambió con la mudanza a una ciudad más grande, ubicada a poco más de 200 kilómetros de la capital provincial. Sus padres se 
integraron como líderes, no pastores, a otra comunidad cristiana y, a su vez, Lucas encontró alguien como él que le permitió reflexionar sobre sus experiencias con la fe:

Conocí a quien era el hijo del pastor de esta iglesia, que se llama Esteban. Esteban era un cristiano concreto más allá de las idealizaciones de lo que deberían ser los cristianos, este era un cristiano bien concreto que tenía mi edad. Fue mi primer amigo y fue una persona en la que vi todas estas aspiraciones de vivir una vida espiritual...tenían que ver con la vida cotidiana; no eran perfectos ni mucho menos pero sí veía que esto que me molestaba tanto de los otros, la hipocresía, por ejemplo, no era así. Y fue un factor importante en el hecho de que yo cambiara o me abriera un poco más a la posibilidad de Dios. Eventualmente, con el paso del tiempo yo también me fui acercando en mis propios términos a la fe (Lucas).

Desde entonces, Lucas ha atravesado momentos de mayor cercanía con Cristo y también instancias de dudas y alejamiento, diversas "crisis espirituales", como las denomina. En especial, un momento de marcada ansiedad social se dio cuando, a los 17 años, se mudó a la ciudad de Córdoba para estudiar una carrera universitaria.

Ese proceso de estudiar Comunicación Social, de acercarme a autores, de participar en debates en la universidad, de estar en contacto con compañeros y demás...que tenían una actitud muy crítica hacia la fe, leer mucho pensamiento marxista, la escuela de Frankfurt, existencialistas y demás, fue un golpe también difícil de asimilar. Se hacían acusaciones muy concretas en contra de la fe cristiana y de qué manera iba a poder responder yo a eso (...) (Lucas).

Con el correr de los años, Lucas viajó a terminar sus estudios a Italia, donde ahora reside su familia, aunque poco después decidió regresar a Córdoba. Sigue participando de diversos grupos cristianos, en especial en la comunidad Aviva, buscando espacios de diálogo y reflexión desde una aproximación que privilegie más "lo intelectual (que) tiene mucho que ver con la fe" más que la dimensión emocional, según sus palabras.

Lucas describe numerosas interacciones cotidianas con personas de otras creencias, las cuales no siempre han sido positivas: 
Me ha pasado en contextos universitarios, me ha pasado en contextos laborales, de grupos de amigos, en el colegio, constantemente. Me he sentido de muchas maneras. Hay gente que sabe dialogar y hay gente que es bastante violenta. Pasa en todos los aspectos. Pasa dentro de los grupos cristianos, pasa con los ateos, pasa junto con los musulmanes, con los budistas; con cualquiera puede pasar. Creo que cualquiera de estos grupos tiene que aprender a dialogar con los otros. (...) No siempre es fácil mantener una sensación de apertura, de buen diálogo, cuando te están violentando. Yo he escuchado decir barbaridades. He escuchado decir: "[l]a gente que piensa lo que vos piensas debiera ser asesinada", por gente muy académica, por gente muy culta y demás (Lucas).

El relato de vida de Lucas resulta significativo por varios motivos que interesan aquí destacar. Por un lado, sus narraciones dan cuenta de que la diversidad religiosa, como el prejuicio interreligioso, no están homogéneamente distribuidos en locaciones y espacios de interacción social. La vivencia de personas que se identificaron como evangélicas y que crecieron en localidades más pequeñas o en algunas localidades del noroeste del país adquieren muchas veces un carácter más marcado de alteridad, en la medida que se perciben como sociedades de fuerte arraigo católico que tienden a exponerlos o marginalizarlos. Esteban, por ejemplo, advierte que las vivencias de su familia que reside en Santiago del Estero son diferentes a las que puede tener él en la ciudad de Córdoba: "la cultura por ahí es algo difícil o completamente distinta a la que tenemos acá", lo cual se lo atribuye a que "la gente tiene un poquito más de identidad de pueblo", mientras que en la ciudad "al haber tanta diversidad de religiones, personas, se juntan muchas cosas".

Incluso entrevistados que no se identificaron como evangélicos refieren a experiencias similares. Andrea, por ejemplo, quien fuera criada como católica en la provincia de Salta, pero en la actualidad no se identifica con una religión, cuenta que en las clases de religión de su escuela se imponía una visión católica por parte de una profesora que "era tremendamente autoritaria". Relata que "en un momento nos manda a hacer unos trabajos sobre sectas, donde para ellos eran los mormones, los evangélicos, o sea todo lo que no era la religión católica" y recuerda que una compañera evangélica "la pasó horrible, pobrecita". 
Por otro lado, las instituciones educativas, como la escuela primaria o la universidad, donde Lucas evidenció diversas formas de animosidad, son los espacios más referidos en donde la diversidad de creencias se presenta como un momento de tensión y ansiedad social significativa para las personas entrevistadas. Si bien existe la creencia extendida en Argentina de que la educación pública es laica, en al menos siete provincias sus constituciones provinciales reconocen de alguna manera la educación religiosa, aunque no se operativice en la práctica (Esquivel, 2014). A su vez, al menos desde la polémica "libre o laica", que reconoció la instalación de universidades privadas, la mayoría de ellas confesionales, la universidad ha sido un reducto significativo para el laicismo en el país. Algunos entrevistados narran la búsqueda de una comunidad de pares que les permita atravesar esa instancia preservando una espiritualidad propia. Por ejemplo, algunos casos dan cuenta de su participación en grupos de estudios bíblicos, como los promovidos por la Asociación Bíblica Universitaria Argentina (ABUA), la cual ha tenido un período de resurgimiento en los últimos años. Otros, como el caso de Carlos, cuentan situaciones de crisis de fe durante el transcurso universitario: "esa fue mi etapa de ateísmo".

Muchas de estas narraciones son retrospectivas y se remontan al menos a una década atrás, lo cual no nos permite afirmar que las situaciones de hostigamiento o desvalorizaciones continúen vigentes en el mismo sentido narrado por las y los participantes del estudio en la actualidad. No obstante, es extendida la percepción de que la existencia de una mayor diversificación religiosa en diversos espacios sociales no implica necesariamente una valoración positiva de esa diversidad. Carolina, quien ha sido criada como evangélica, pero se mantiene al margen de las iglesias por las que ha transitado, lo sintetiza de la siguiente forma:

Se han puesto de moda las cuestiones más orientales ahora $y . . . y$, como está de moda es canchero y... si vos venís a decir que sos evangélico, u otro religioso, sos un chiste, pero si haces prácticas Feng Shui o cosas por el estilo, está todo bien, y sí, está metido en la sociedad, claro que sí (Carolina). 


\section{"Querían alguien de confianza [y] nadie más de confianza que un evangélico"}

Carolina tiene 31 años y creció en una familia evangélica. "Crecí con Dios dando vuelta en la familia todo el tiempo", aunque señala que la religión "nunca trastocaba la rutina familiar" y tampoco "la iglesia era una actividad de todos los días". Asistió a un colegio religioso cristiano, del cual guarda recuerdos mayormente positivos, pero que rememora con cierto distanciamiento debido a ciertas posiciones rígidas de algunos docentes. Por ejemplo, una docente solía desafiarla porque veía Los Simpsons, serie que consideraba "diabólica".

Durante la adolescencia dejó de congregar porque "me cansó, me aburrió, nunca me entusiasmó", aunque "aún Dios sigue siendo [importante] para mí" y se comunica con él todo el tiempo. A su vez, la iglesia de los Hermanos Libres, de la cual era parte, le resultó "demasiado conservadora". Durante la universidad, donde estudió para ser traductora y profesora de inglés, Carolina atravesó un proceso de búsqueda espiritual: frecuentó misas en la iglesia católica de la Compañía de Jesús, visitó otros templos e integró el grupo de estudios bíblicos de ABUA, para luego organizar con otras compañeras su propio grupo de estudios bíblicos. En la actualidad se desempeña como empleada de una tienda de regionales y artesanías a la que suelen frecuentar turistas que ella atiende en inglés. "En el negocio son todos familia y amigos y que metieran a alguien de afuera... querían que fuera alguien de confianza y lo convencieron a mi jefe que nadie más de confianza que un evangélico", cuenta. No obstante, al momento de la entrevista Carolina se identifica como "sin religión", por lo cual aclara: "después se enteraron de que yo ya no era evangélica, yo no me consideraba evangélica, pero venía de ese lado, así que tenía chapa de confiable".

El trabajo aparece en varias de las narrativas como instancias donde la diversidad de creencias puede generar tensiones, aunque también puede ser sometida a una regulación particular por parte de algunos cristianos evangélicos.

Por un lado, actitudes y prácticas de animosidad aparecen en algunas narrativas asociadas a los espacios laborales donde la diversidad religiosa es marcada, y donde la persona evangélica queda más expuesta en su 
alteridad. Ramiro, por ejemplo, soltero de 38 años quien se desempeña en una metalúrgica, narra que muchas veces es objeto de hostigamiento por parte de sus compañeros. "Es un ambiente muy machista. Son 300 hombres. Y todo el tiempo se están burlando de mí". ¿El motivo? Porque no sale con nadie. "Ellos me instan, todo el tiempo, a que viva la vida. Ellos la ven - a la vida - como el hecho de estar con muchas mujeres" y para él, desde sus creencias, no tiene sentido salir con alguien si "no es en serio". Para Ramiro, "Dios dice que no nos podemos juntar dos personas que tengan distinta fe", por lo cual, si bien desea formar una familia, afirma que no ha encontrado a nadie "de la misma fe" que después "no te da problemas en tu casa".

Como en el caso de Ramiro, Olivia cuenta que "varios de mis compañeros se han burlado o me han escondido cosas" mientras ella trabajaba como encargada de un bar. En su relato, la otredad se construye a partir de su posicionamiento ético, que no resultaba equivalente al de sus compañeros. Mientras "sacaban a escondidas una Coca-Cola (...) o faltaba plata de la caja", ella se lo decía a la dueña del local. "Yo siempre me manejé con la verdad", afirma, "y no era de botona... (...) si la dueña me preguntaba, ¿jpor qué voy a mentir?".

Rafael, quien se desempeña en una multinacional tecnológica, narra que durante mucho tiempo sus compañeros "prácticamente no me dirigían la palabra (...) porque iba a la Iglesia y cosas así". Lleva ya diez años trabajando en la misma empresa y afirma que con el tiempo el aislamiento ha ido remitiendo y "hablamos comúnmente con todos los empleados". Para él, "la oración me ayudó mucho" a atravesar esos momentos de tensiones en su ámbito laboral: "Yo oro mucho para descargar la ansiedad y dejarle a Dios los problemas en sus manos".

Frente a estas situaciones, la preferencia de trabajar con cristianos es una idea que emerge con frecuencia en varias de las entrevistas. Algunos mencionan que estos espacios son "confortables" y "cuidados en lo espiritual", lo cual permite aún más evidenciar la existencia de otros espacios de trabajo que no son percibidos como tales. La posibilidad que algunos cristianos tienen de gestionar contextos de trabajo como "espacios seguros" se presenta como diferencial. En estos, se opta por la evitación del contacto interreligioso y con no creyentes. Señalan una ética de trabajo 
particular entre cristianos, una forma en que la propia espiritualidad se compromete en el hacer del día a día, y que puede ayudar a gestionar las tensiones reales o potenciales que surgen con las "personas de mundo" en esos ámbitos. Carolina es seleccionada para trabajar en un ambiente gestionado por evangélicos, por la "chapa de confiable" que le otorga su pasado evangélico.

Alfredo y su mujer, por ejemplo, trabajan en diversos ambientes cristianos. Alfredo es diseñador gráfico y su mujer administrativa en Cita por la vida. Alfredo afirma que su trabajo es un "discipulado" y que incluso cuando realiza trabajos como freelancer la mayoría de sus clientes son evangélicos o lo conocen a través de sus trabajos en y para la iglesia. La prédica y la oración son el combustible habitual de lo que hace: "Antes de diseñar yo oro, yo creo que está conectado, (...) trato de estar conectado todo el tiempo (...) antes de sacar fotos, yo le pido a Dios que me de sabiduría...".

Marta, por su parte, si bien no todas sus vendedoras son evangélicas, advierte que prefiere trabajar con personas cristianas o al menos creyentes:

No dejo pasar la oportunidad de que quien trabaje conmigo sepa que nosotros tenemos pautas de respeto, de integridad, de transparencia en todo lo que hacemos. (...) Confío en las personas, quiero que me conozcan de esta forma. (...) En cada reunión de trabajo yo no dejo de recordarles que este trabajo Dios me le dio. Este trabajo no es mérito mío. Dios me ha dado y me da las personas para trabajar y me da las oportunidades y le doy gracias a Dios cada día por trabajar con ellos y por tener este trabajo.

En algún caso, a partir de las propias experiencias vividas, se cuestiona esta preferencia. La historia más Ilamativa es la que narra Mónica, preceptora y docente de 58 años, quien durante casi trece años se desempeñó como administrativa en una asociación mutual cristiana. "De alguna manera estos proyectos en los que 'nosotros somos cristianos y que somos los mejores porque contamos con la bendición de Dios' son un gran peligro", señala. La empresa "se fundió", debido al desmanejo económico que realizaron algunos empleados y la falta de controles. 
Éramos todos creyentes (...) hacíamos el devocional todas las mañanas todos juntos, me acuerdo que venía gente y que ponía su dinero en plazo fijo porque funcionaba como financiera y les hablábamos de Dios, y fue un horror... (Mónica).

Desde entonces, Mónica afirma que "me quedó alergia de trabajar en los proyectos evangélicos (risas)".

La gestión de espacios seguros para cristianos también puede implicar diferencias según la iglesia en la cual cada persona congregue. En este sentido, las preferencias se presentan asociadas con las redes sociales que contiene la propia comunidad religiosa. Así lo señala Alejandra, quien cuenta una experiencia en la que en una entrevista laboral le manifestaron que buscaban personas de una iglesia en particular:

Y, bueno, las otras chicas me decían: "bueno, vos decile que vas a venir a la Iglesia, total, no se van a enterar o vení algunas veces como para que ellos te vean". Y yo dije: "no, yo no voy a ir, porque yo ya tengo mi congregación, mi Iglesia y no voy a hacer algo por un trabajo". Si es la voluntad de Dios que yo entre, voy a entrar, pero porque es la voluntad de Dios. No por mentiras ni engaño (Alejandra).

\section{"Que podamos demostrar que Cristo vive en nosotros"}

Alejandra tiene 39 años, tres hijas y es ama de casa. Su marido trabaja como empleado de la construcción en una empresa desarrollista. Alejandra está muy activa en su iglesia: además de congregar todos los domingos, coordina una célula de mujeres en su hogar los jueves, los viernes participa de otra célula en su barrio, y los lunes lleva a sus hijas a una célula de niños. Toda su rutina familiar está atravesada por lo devocional: "Siempre oramos a la mañana para que la moda de este mundo, las cosas que pasan en este tiempo, no nos las contaminen". Para Alejandra, la fe es importante para sostener a su familia. Guarda recuerdos tristes de la conflictiva separación de sus padres y considera que, gracias a su fe y a la participación en la iglesia, ellos no repetirán la misma historia. Junto con su marido, a su vez, son militantes del Movimiento Evita, un movimiento social y sindical, de 
extracción popular, creado en 2004 bajo el amparo del Frente para la Victoria (kirchnerismo).

En la historia de Alejandra la diversidad religiosa es una realidad cotidiana. La familia vive en un sector empobrecido de la ciudad, frente a una parroquia católica que ofrece talleres culturales y recreativos a jóvenes del barrio al cual suelen concurrir algunas de sus hijas. Su familia de origen incluye miembros de diversas iglesias evangélicas, católicos y algunos sin religión. Entre sus compañeros de militancia también identifica diversidad de creencias y, sobre todo, de estilos de vida. Algunos "están ahí, fumando porro, o son groseros", lo cual no le gusta, y se lo señala a sus hijas, aunque siguen militando. A la hora de interactuar con otros, señala:

Yo siempre les digo a las chicas que los demás no sepan que somos cristianos porque lo tengamos que decir, sino que nuestras actitudes, nuestros pensamientos, nuestra forma de tratar, de resolver las cosas, que pueda ser diferente, ¿no? Que podamos demostrar que Cristo vive en nosotros (Alejandra).

Por lo general, no se ha sentido discriminada, aunque afirma que "si me discriminan por ser diferente, por hacer lo bueno, me encanta". Sin embargo, poco antes de las entrevistas se enteró de que una amiga había decidido no invitarla a su despedida de soltera "porque era cristiana y decían que, como que era muy aburrida (risas)".

En casi todas las experiencias que relata Alejandra se advierten modulaciones y negociaciones particulares con "el mundo ahí afuera". Por ejemplo, en el jardín al que asiste una de sus hijas se celebró un ritual para la Pachamama, lo cual habilitó una discusión al interior familiar, dado que ambos padres preferían que la hija no concurriera ese día a la escuela, "porque no queríamos que (...) escuchara esas historias o hiciera algo que a Dios no le agrada". Su hija, en cambio, quería ir y prometió que no haría lo que sus compañeritos hacían. Finalmente, se lo permitieron. Y el cumplimiento de la promesa de su hija fue confirmada por la maestra cuando Alejandra la fue a recoger ese día al jardín: "No hizo nada de lo que hicieron sus compañeritos... Para mí fue una emoción, yo lloraba", cuenta.

En su militancia también se han dado circunstancias que han implicado negociaciones específicas entre sus creencias y su convicción política. Por ejemplo, cuando el movimiento decidió participar de una marcha a favor 
de la legalización del aborto, tanto ella como su marido decidieron no intervenir. Por el contrario, junto con miembros de la iglesia, marcharon en contra de la iniciativa por las calles céntricas de la ciudad. También el movimiento convocó a una movilización en torno a la celebración de San Cayetano, donde se reivindicaban banderas por tierra, techo y trabajo. "Y mi pensamiento era que no me gustaba que participaran de la marcha (su esposo y su hija mayor)", pero finalmente los acompañó porque

mi esposo me decía que no tenía que mezclar una cosa con la otra... O sea, Dios sabe que nuestro sentir, nuestro pensamiento, no era ir a agradecer a San Cayetano, porque en realidad el que nos provee es El Señor, nada más (Alejandra).

Los modos en que Alejandra y su familia parecen gestionar sus interacciones con "otros" religiosos se presentan como negociaciones particulares en cada caso, donde prima la búsqueda de una autodeterminación que privilegia la importancia y la conciencia personal, por sobre la congruencia o la conformidad social. La resignificación de la intervención en espacios o prácticas que puedan tensionar con las propias creencias parece ser un camino a través del cual ella y su familia han podido sostener un contacto no "contaminante" con el mundo.

\section{Conclusiones}

El presente trabajo ha buscado explorar los modos en que las personas evangélicas de la ciudad de Córdoba, Argentina, perciben su posición en un contexto de creciente visibilidad de la diversidad religiosa y no religiosa, y cómo y en qué espacios se dan situaciones de interacción intergrupal, a lo largo del entramado de sus interacciones cotidianas. Para ello hemos recuperado mayormente referencias de tres historias de vida (Lucas, Carolina y Alejandra), aunque las reflexiones que cada una de ellas habilita nos han permitido identificar experiencias análogas o particularidades con las narrativas de otros participantes del estudio.

En primer término, a través de la historia de Lucas, "el único chico evangélico de mi edad" en un pequeño pueblo de la zona agrícola de la provincia de Córdoba, es posible advertir cómo la diversidad religiosa no se 
encuentra (o, al menos, no se encontraba) distribuida de manera homogénea en los diversos espacios sociales y localidades. En localidades pequeñas y en ciudades del noroeste de Argentina, para quienes crecieron en esos entornos, se advierte una regulación social que supone una sociedad de fuerte arraigo católico, lo cual los sitúa en la posición del "otro" religioso de forma indiscutida. Los sentimientos de otredad se configuran a partir de aislamientos, hostigamientos, a veces expresiones sutiles y otras manifiestas de prejuicio que se evidencian en muy diversos espacios: en los distintos niveles de las instituciones educativas, en el trabajo, en el grupo de amistades, o incluso en la propia comunidad religiosa. En efecto, para Lucas, como para otros participantes del estudio, la comunidad religiosa no siempre es un espacio de acogida emocional; en algunos casos, el intragrupo puede manifestar también prejuicios y hostigamientos, lo cual contribuye a ahondar más en la propia sensación de otredad. Esto se advierte en particular entre quienes se encuentran actualmente "apartados" de sus iglesias, no congregan o han dejado de identificarse como evangélicos, pero también se ha reportado, por ejemplo, entre cristianos evangélicos que se identifican como gays o lesbianas en diversos contextos (Johnson; Aguirre, 2017; Rodríguez, 2009).

En el trabajo, la categorización del "otro" religioso también puede conducir a tensiones y manifestarse en hostigamientos, como se advierte en las referencias de Olivia, Rafael y Ramiro. No obstante, el espacio laboral, a diferencia de las instituciones educativas, se presenta en varios casos como una instancia donde las propias personas evangélicas pueden gestionar la (no)diversidad religiosa deseada, a partir de la evitación de contacto. "Nadie más de confianza que un evangélico", afirma Carolina, para dar cuenta de los motivos que condujeron a su contratación en un negocio administrado por una familia evangélica. A partir de procesos de diferenciación intergrupal con lo "mundano", algunas personas han buscado construir "espacios seguros", "confortables", integrados por evangélicos y, en algunos casos, de forma exclusiva por miembros de la propia iglesia. En estos contextos, el trabajo se articula con prácticas devocionales diarias y con dar "profesión de fe", como identificara Espinosa (2014) en dos empresas, una de gestión evangélica y otra asociada a la Renovación Carismática Católica (RCC) en Córdoba. A partir de algunas experiencias, como la de 
Mónica, se cuestiona la idealización de las condiciones y competencias de las personas que optan por emprendimientos conformados de manera intragrupal, aunque la preferencia por estos espacios resulta bastante extendida entre nuestros entrevistados.

En tercer término, a partir de la historia de Alejandra, es posible advertir que diversos contactos intergrupales generan, si no un conflicto, al menos una situación de ansiedad, que cada persona y en cada contexto busca gestionar a su modo. Puede darse una participación resignificada (participar de la movilización de San Cayetano pero acompañando las reivindicaciones sociales y no el culto al santo católico), como meros testigos (ir al jardín y presenciar la celebración de la Pachamama, sin intervenir activamente), o bien una compartimentalización de las instancias en las cuales se produce la participación (no asistir a la marcha a favor de la legalización del aborto a la cual convocaba la agrupación para la cual militan, pero sí asistir a la movilización en contra de la iniciativa junto con otros miembros de su iglesia).

Así, algunas personas entrevistadas enfatizan su autonomía personal a la hora de decidir dónde y cómo intervenir en el mundo. La búsqueda de dar cuenta de las propias prácticas desde un registro que se pretende autónomo y personal constituye un fenómeno extendido en todas las personas que participaron del estudio en Córdoba, no solo evangélicas (Rabbia, 2019). No obstante, es más correcto pensar en cómo las motivaciones extrínsecas (reguladas externamente) se presentan como un continuum con diversos grados de autodeterminación, especialmente en aquellas prácticas que suponen algún nivel de tensión entre lo que uno cree y lo que uno quiere, entre lo esperable por parte de la comunidad religiosa, y lo que implica la práctica en sí (Ryan; Deci, 2000). La autodeterminación de las prácticas no suele ser un atributo que el espacio social parece atribuirle a las personas evangélicas en general. Por el contrario, desde diversas miradas generalizantes, se tiende a pensar que las personas evangélicas actúan por inercias, compromisos o presiones, es decir, por locus causales externamente regulados.

En efecto, a partir de diversos elementos en las narrativas, se percibe que el entorno social les asigna un bajo status a evangélicos, donde diversos estereotipos cuestionan sus competencias para la interacción social (por ejemplo, su rigidez moral, como en las historias narradas por Alejandra con 
sus amigas, o en los casos de Ramiro u Olivia en sus trabajos). Similar a lo que señalaran Griera i Llonch e Iglesias i Sala (2004), entre las personas entrevistadas resulta extendida la percepción de una valoración diferenciada de las diversas tradiciones religiosas en el contexto social ampliado, una jerarquía más o menos delineada de expresiones religiosas en espacios públicos y semipúblicos, que despierta actitudes diferenciales para cada caso. Parafraseando a una de nuestras entrevistadas, ser cristiano "no está de moda".

El prejuicio anticristiano, y hacia personas evangélicas en particular, es una cuestión escasamente explorada (Moulin, 2016), y puede ser un campo de estudios promisorio para la Sociología y la Psicología Social de la religión en la región. Como propone la teoría socio-funcional del prejuicio (Cook et al., 2015), estos estereotipos podrían explicarse a partir de las sensaciones de amenaza que despierta el exogrupo por parte de otros grupos. Esta teoría, también conocida como teoría de la amenaza integrada, postula que las expresiones de prejuicio pueden ser, en parte, explicadas por la percepción que tienen miembros del endogrupo respecto a que personas de un exogrupo se comportarán de maneras amenazantes o perjudiciales hacia ellos, a la vez que la cantidad y las características de los contactos integrupales pueden conducir a una mayor percepción de amenaza (Stephan; Diaz-Loving; Duran, 2000). El entorno social también puede ayudar en los procesos de estereotipia que conforman a determinados grupos como "amenazantes", más aún en contextos de mayor visibilidad de la diversidad religiosa. Así, las etiquetas asociadas a los debates sobre el problema de las sectas (Frigerio; Wynarczyk, 2008) o, más recientes, al fundamentalismo conservador (Flores, 2019), es decir, las imágenes estereotipadas de evangélicos, parecen inscribirlos en diversas circunstancias como un "otro" amenazante, aspecto que requiere de mayores profundizaciones a futuro. A su vez, los prejuicios de los que se sienten objeto algunas de las personas entrevistadas pueden articularse con sus propios prejuicios, en particular hacia personas gays y lesbianas y hacia personas sin religión. Aunque estas posiciones no son homogéneas ni exclusivas de evangélicos, y se modulan de forma considerable según la edad y el nivel socioeconómico, varias personas entrevistadas mostraron creencias férreas en el carácter natural y deseable de la heterosexualidad, 
y la defensa del matrimonio tradicional entre varón y mujer, a la vez que cuestionaron al ateísmo, desde su presunta irracionalidad, la falta de agencia moral, y la imposibilidad del "no creer" en Dios. Conocer cómo se dan las articulaciones entre personas de un grupo percibido como un "otro", construido como amenaza, con sus propios prejuicios intergrupales, podría contribuir a desarticular los prejuicios en ambas direcciones.

Hugo H. Rabbia es Doctor en Estudios Sociales de América Latina, Investigador Asistente del CONICET en IIPsi, Facultad de Psicología, Universidad Nacional de Córdoba, y profesor en la Facultad de Ciencia Política y Relaciones Internacionales en la Universidad Católica de Córdoba, Argentina.

$\equiv$ hrabbia@conicet.gov.ar.

\section{Referencias}

1. ALLPORT, Gordon W. The religious context of prejudice. Journal for the Scientific Study of Religion, v. 5, n. 3, p. 448-451, 1966. https://www.jstor.org/ stable/1384172

2. AMEIGEIRAS, Aldo R. Religiosidad popular. Creencias religiosas populares en la sociedad argentina. Los Polvorines: UNGS Biblioteca Nacional, 2008.

3. AMMERMAN, Nancy T. Sacred stories, spiritual tribes: finding religion in everyday life. New York: Oxford University Press, 2014.

4. BATSON, C. Daniel.; SCHOENRADE, Patricia A. Measuring religion as quest 1: validity concerns. Journal for the Scientific Study of Religion, v. 30, n. 4, p. 416429, 1991. https://www.jstor.org/stable/1387277

5. CARBONELLI, Marcos. Los evangélicos y la arena partidaria en la Argentina contemporánea. Estudios Políticos, v. 37, p. 193-219, 2016. https://doi. org/10.1016/j.espol.2016.02.008

6. CAROZZI, Maria J. Nueva Era y terapias alternativas. Construyendo significados en el discurso y en la interacción. Buenos Aires: EDUCA, 2000.

7. CHAPPLE, Simon; PRICKETT, Kate. Who do we trust in New Zealand? 2016 to 2019. Victoria University of Wellington: Nueva Zelanda, 2019. Disponible en: https://www.victoria.ac.nz/_data/assets/pdf_file/0011/1762562/ trust-publication-2019.pdf

8. COOK, Corey L.; COTTRELL, Catherine A.; WEBSTER, Gregory D. No good without God: antiatheist prejudice as a function of threats to morals and values. Psychology of Religion and Spirituality, v. 7, n. 3, p. 217-226, 2015. https://doi. org/10.1037/rel0000013 
9. DE LA CALLE, Enrique. "Si decís que todos los evangélicos son de derecha, vas a terminar agrupándolos en la derecha", entrevista a Néstor Miguez. Agencia Paco Urondo. Debates, 20 dic. 2018. Disponible en: http://www.agenciapacourondo. com.ar/debate/si-decis-que-todos-los-evangelicos-son-de-derecha-vas-terminaragrupandolos-en-la-derecha

10. DE LA TORRE, Renée; GUTIERREZ-ZUÑIGA, Cristina. Tendencias a la pluralidad y la diversificación del paisaje religioso en el México contemporáneo. Sociedade e Estado, v. 23 n. 2, p. 381-424, 2008. http://dx.doi.org/10.1590/ S0102-69922008000200007

11. DEIROS, Pablo A. Historia del cristianismo: el testimonio protestante en América Latina. Buenos Aires: Ed. Del Centro, 2013.

12. EN EL INADI, denuncias por religión y género. Eldia.com. 10 nov. 2017. Disponible en: https://www.eldia.com/nota/2017-11-10-3-48-44-en-el-inadidenuncias-por-religion-y-genero-informacion-general

13. ESPINOSA, Mariana E. Religión, clases de habitus y economía. Una etnografía de empresas cristianas. Revista Cultura y Religión, v. 8, n. 2, p. 232-246, 2014.

14. ESQUIVEL, Juan C. Religión y política en Argentina. La influencia religiosa en las Constituciones provinciales. Revista de Direito da Cidade, v. 6, n. 2, p. 348368, 2014. http://dx.doi.org/10.12957/rdc.2014.13451

15. ETCHEZAHAR, Edgardo; UNGARETTI, Joaquín; RABBIA, Hugo H. ¿Por qué nos cuesta tanto vivir juntos/as? Una mirada psico-política del prejuicio, los estereotipos y la discriminación. In: BRUSSINO, Silvina (coord.). Políticamente. Contribuciones desde la psicología política en Argentina. Buenos Aires: CONICET, 2018. p. 210-230.

16. FLORES, Fabián. El "peligro" evangélico. Polvo [en línea]. 6 feb. 2019. Disponible en: http://www.polvo.com.ar/2019/02/fabian-flores-evangelismo/

17. FORNI, Floreal. Emergencia de nuevas corrientes religiosas o "Iglesias alternativas" sobre fines de siglo. Sociedad y Religion, v. 9, p. 40-47, 1992.

18. FRIGERIO, Alejandro. Nuevos movimientos religiosos y ciencias sociales. $v$. 1. Buenos Aires: Centro Editor de América Latina, 1993.

19. FRIGERIO, Alejandro; WYNARCZYK, Hilario. Diversidad no es lo mismo que pluralismo: cambios en el campo religioso argentino (1985-2000) y lucha de los evangélicos por sus derechos religiosos. Sociedade e Estado, v. 23, n. 2, p. 227 260, 2008. http://dx.doi.org/10.1590/S0102-69922008000200003

20. GARCÍA BOSSIO, María P. Regulación estatal de lo religioso en la Provincia de Buenos Aires: su incidencia en la elaboración de políticas públicas. In: IX Jornadas de Sociología de la UNLP, 2016. Disponible en: http://www.memoria. fahce.unlp.edu.ar/trab_eventos/ev.8974/ev.8974.pdf

21. GERVAIS, Will M.; SHARIFF, Azin F.; NORENZAYAN, Ara N. Do you believe in atheists? Distrust is central to anti-atheist prejudice. Journal of Personality and Social Psychology, v. 101, n. 6, p. 1189-1206, 2011. https://doi.org/10.1037/ a0025882 
22. GRIERA I LLONCH, Maria; IGLESIAS I SALA, Augusti. Les estratègies de legitimació dels grups religiosos minoritaris. Revista Catalana de Sociologia, $\mathrm{n}$. 19, p. 229-260, 2004. https://www.raco.cat/index.php/RevistaSociologia/article/ view/15552

23. HALL, Bradford J. Narratives of prejudice. Howard Journal of Communication, v. 9, n. 2, p. 137-156, 2010. https://doi.org/10.1080/106461798247069

24. INADI - Instituto Nacional Contra la Discriminación, el Racismo y la Xenofobia. Mapa nacional de discriminación. Segunda edición. Buenos Aires: INADI, 2014.

25. JENSEN, Sune Q. Othering, identity formation and agency. Qualitative Studies, v. 2, n. 2, p. 63-78, 2011. https://doi.org/10.7146/qs.v2i2.5510

26. JOHNSON, María C.; AGUIRRE, David A. Ovejas apartadas: sexualidades disidentes, religiosidad y familia. Religião e Sociedade, v. 37, n. 1, p. 47-64, 2017. http://dx.doi.org/10.1590/0100-85872017v37n1cap03.

27. JONES, Daniel; CARBONELLI, Marcos A. La participación política de actores religiosos: los evangélicos frente a los derechos sexuales y reproductivos (20032010). In: ESQUIVEL, Juan C.; VAGGIONE, Juan M. (dirs.). Permeabilidades activas: religión, política y sexualidad en la Argentina democrática. Buenos Aires: Biblos, 2015. p. 75-95.

28. LEVINE, Daniel H. Pluralidad, pluralismo y la creación de un vocabulario de derechos. América Latina Hoy, n. 41, p. 17-34, 2005.

29. LISTER, Ruth. Poverty. Cambridge: Polity Press, 2004.

30. MAIOLI, Esteban. Discriminación de minorías religiosas en la Argentina. Una revisión de las prácticas sociales discriminatorias aplicadas a la iglesia de los testigos de Jehová. In: IX Jornadas de Sociología. Facultad de Ciencias Sociales, UBA, 2011. Disponible en: http://cdsa.aacademica.org/000-034/838.pdf

31. MALLIMACI, Fortunato.; GIMÉNEZ-BÉLIVEAU, Verónica.; ESQUIVEL, Juan C.; IRRAZÁBAL, Gabriela. Segunda Encuesta Nacional sobre Creencias y Actitudes Religiosas en Argentina. Sociedad y Religión en Movimiento. Informe de Investigación 25. Buenos Aires: CEIL-CONICET, 2019. Disponible en: http:// www.ceil-conicet.gov.ar/2019/11/segunda-encuesta-nacional-sobre-creencias-yactitudes-religiosas-en-la-argentina/

32. MAROSTICA, Matt. La iglesia evangélica en la Argentina como nuevo movimiento social. Sociedad y Religión, n. 12, p. 3-16, 1994.

33. MARTIN, David. Tongues of fire: the explosion of protestantism in Latin America. Oxford: Blackwell. 1990.

34. MCNAMARA, Tim. Theorizing social identity; what do we mean by social identity? Competing frameworks, competing discourses. TESOL Quarterly, v. 31, n. 3, p. 561-567, 1997. https://www.jstor.org/stable/3587838

35. MÍGUEZ, Daniel. El protestantismo popular en la Argentina. Las lógicas de expansión del pentecostalismo durante el siglo XX. In: CERIANI CERNADAS, César; ESPINOSA, Mariana (comps.). Argentina evangélica: estudios socioantropológicos 
sobre misiones e iglesias. Córdoba: CONICET/IDACOR y Bellas Alas Ed., 2018. p. 51-109.

36. MORELLO, Gustavo; RABBIA, Hugo H. Introducción: cómo se vive la religión en Sudamérica. In: RABBIA, Hugo H.; MORELLO, Gustavo; DA COSTA, Néstor; ROMERO, Catalina (comps.). La religión como experiencia cotidiana: creencias, prácticas y narrativas espirituales en Sudamérica. Córdoba, Lima, Montevideo: EDUCC, Fondo Editorial PUCP, UCU, 2019. p. 9-27.

37. MOULIN, Daniel. Reported experiences of anti-christian prejudice among christian adolescents in England. Journal of Contemporary Religion, v. 31, n. 2, p. 223-238, 2016. https://doi.org/10.1080/13537903.2016.1152679

38. NÚÑEZ ALARCÓN, Máximo; MORAL TORANZO, Félix; MORENO JIMÉNEZ, María del P. Impacto diferencial de la religión en el prejuicio entre muestras cristianas y musulmanas. Escritos de Psicología, v. 3, n. 4, p. 11-20, 2010.

39. PÁEZ, José I.; RABBIA, Hugo H.; HEVIA, Guillermo E.; PESCI, Florencia. Bases sociales y psicopolíticas del prejuicio hacia personas trans en habitantes de Córdoba, Argentina. Investigaciones en Psicología, v. 23, n. 2, p. 27-36, 2018. https://doi.org/10.32824/investigpsicol.a23n2a3

40. PARKER-GUMUCIO, Cristián. ¿América Latina ya no es católica? Pluralismo cultural y religioso creciente. América Latina Hoy, v. 41, p. 35-56, 2005.

41. PETTIGREW, Thomas. Intergroup contact theory. Annual Review of Psychology, v. 49, n. 1, p. 65-85, 1998. https://doi.org/10.1146/annurev. psych.49.1.65

42. PEW RESEARCH CENTER. Religion in Latin America. Widespread change in a historically catholic region. Pew Research Center [web page]. Religion and Public Life. 13 nov., 2014. Disponible en: http://www.pewforum.org/2014/11/13/ religion-in-latin-america

43. RABBIA, Hugo H.; GATICA, Lucas. Being a Roman Catholic in a context of religious diversity. An exploration of lived religion among cCatholics in Córdoba, Argentina. Visioni LatinoAmericane, v. 17, p. 38-64, 2017. Disponible en: http:// hdl.handle.net/10077/18470

44. RABBIA, Hugo H. Sobre identificaciones, congruencia religiosa y la autonomía de personas creyentes. In: RABBIA, Hugo H.; MORELLO, Gustavo.; DA COSTA, Néstor; ROMERO, Catalina (Eds.). La religión como experiencia cotidiana: creencias, prácticas y narrativas espirituales en Sudamérica. Córdoba, Lima, Montevideo: EDUCC, Fondo Editorial PUCP, UCU, 2019. p. 33-46.

45. RODRÍGUEZ, Eric. At the intersection of church and gay: a review of the psychological research on gay and lesbian Christians. Journal of Homosexuality, v. 57, n. 1, p. 5-38, 2009. https://doi.org/10.1080/00918360903445806

46. ROLDÁN, Verónica. Formas de religiosidad de fin de milenio: el movimiento carismático católico en Buenos Aires y Roma. Sociedad y Religión, n. 18/19, p. 73-98, 1999. 
47. ROMERO, Catalina. Diversidad religiosa en el Perú. Miradas múltiples. Lima: Fondo Editorial PUCP, 2016.

48. RYAN, Richard M.; DECl, Edward L. Self-determination theory and the facilitation of intrinsic motivation, social development and well-being. American Psychologist, v. 55, n. 1, p. 68-78, 2000.

49. SEMÁN, Pablo. Cosmológica, holista y relacional: una corriente de la religiosidad popular contemporánea. In: CERIANI CERNADAS, César; ESPINOSA, Mariana (comps.). Argentina evangélica: estudios socioantropológicos sobre misiones e iglesias. Córdoba: CONICET/IDACOR y Bellas Alas Ed., 2018. p. 249283.

50. SEMÁN, Pablo. ¿Quiénes son? ¿Por qué crecen? ¿En qué creen? Pentecostalismo y política en América Latina. Nueva Sociedad, n. 280, p. 26-46, 2019.

51. SOMMA, Nicolás; BARGSTED, Matias; VALENZUELA, Eduardo. Mapping religious change in Latin America. Latin America Politics and Society, v. 59, n. 1, p. 120-142, 2017. https://doi.org/10.1111/laps.12013

52. STEPHAN, Walter G.; DIAZ-LOVING, Rolando; DURAN; Anne. Integrated threat theory and intercultural attitudes Mexico and the United States. Journal of Cross-Cultural Psychology, v. 31, n. 2, p. 240-249, 2000.

53. STOLL, David. Is Latin America turning protestant? Berkeley: University of California Press, 1990.

54. STRABAC, Zan; LISTHAUG, Ola. Anti-Muslim prejudice in Europe: a multilevel analysis of survey data from 30 countries. Social Science Research, n. 37, p. 268-286, 2008. https://doi.org/10.1016/j.ssresearch.2007.02.004

55. SUÁREZ, Ana L. Creer en las villas. Devociones y prácticas religiosas en barrios precarios de la ciudad de Buenos Aires. Buenos Aires: Biblos, 2015.

56. TAJFEL, Henri. Grupos humanos y categorías sociales. Barcelona: Herder, 1984.

57. WYNARCZYK, Hilario. Ciudadanos de dos mundos: el movimiento evangélico en la vida pública argentina 1980- 2001. Buenos Aires: UNSAM, 2009.

58. WYNARCZYK, Hilario; SEMÁN, Pablo. Campo evangélico y pentecostalismo en la Argentina. In: CERIANI CERNADAS, César; ESPINOSA, Mariana (comps.). Argentina evangélica: estudios socioantropológicos sobre misiones e iglesias. Córdoba: CONICET/IDACOR y Bellas Alas Ed., 2018. p. 31-46.

59. YANCEY, George. Who has religious prejudice? Differing sources of antireligious animosity in the United States. Review of Religious Research, v. 52, n. 2, p. 159171, 2010. https://www.jstor.org/stable/23054151

Recibido: 10 dic. 2019. Aceptado: 11 feb. 2020. 